\title{
Prevent the Risk of Lung Cancer Progression Based on Fuel Ratio Optimization
}

\author{
${ }^{1}$ Amirzubir Sahamijoo, ${ }^{1}$ Farzin Piltan, ${ }^{1}$ Sareh Mohammadi Jaberi and ${ }^{1,2}$ Nasri b \\ Sulaiman \\ ${ }^{1}$ Intelligent System and Robotic Lab, Iranian Institute of Advance Science and \\ Technology (IRAN SSP), Shiraz/Iran \\ ${ }^{2}$ Department of Electrical and Electronic Engineering, Faculty of Engineering, \\ University Putra Malaysia, Malaysia \\ Email: piltan_f@iranssp.com,WWW.IRANSSP.COM/english
}

\begin{abstract}
Lung cancer, also known as carcinoma of the lung or pulmonary carcinoma, is a malignant lung tumor characterized by uncontrolled cell growth in tissues of the lung. Cancer develops following genetic damage to DNA and epigenetic changes. These changes affect the normal functions of the cell, including cell proliferation, programmed cell death (apoptosis) and DNA repair. As more damage accumulates, the risk of cancer increases. Smoking, radon gas, asbestos, air pollution and genetics are the main causes to increase the rate of lung cancer. Outdoor air pollution has a large effect on increasing the risk of lung cancer. In this research, intelligent technique is presented as robust control of fuel ratio for internal combustion (IC) engine. Computed fuel-ratio controller (CFC) is one of the types of feedback linearization nonlinear controller. This controller works very well in certain positions. The main challenge in CFC is instability in presence of uncertainties. In this research low pass filter is used to improve the stability in CFC. To improve the result of this controller intelligent CFC is recommended based on fuzzy logic technique. In this research fuzzy logic theory is used to tune the new low pass filter CFC coefficients. The process of setting of integral intelligent Computed Fuel-ratio Controller can be determined as an optimization task.
\end{abstract}

Keywords: Lung Cancer, IC Engine, air pollution, computed fuel control, fuzzy logic theory, low pass filter

\section{Introduction and Background}

Lung cancer, also known as carcinoma of the lung or pulmonary carcinoma, is a malignant lung tumor characterized by uncontrolled cell growth in tissues of the lung. If left untreated, this growth can spread beyond the lung by process of metastasis into nearby tissue or other parts of the body. Most cancers that start in the lung, known as primary lung cancers, are carcinomas that derive from epithelial cells. The main primary types are small-cell lung carcinoma (SCLC) and non-small-cell lung carcinoma (NSCLC). The most common symptoms are coughing (including coughing up blood), weight loss, shortness of breath, and chest pains [1]. The vast majority (80-90\%) of cases of lung cancer are due to long-term exposure to tobacco smoke and air pollution [1-2]. About $10-15 \%$ of cases occur in people who have never smoked [3] These cases are often caused by a combination of genetic factors[4] and exposure to radon gas [4], asbestos [5] or other forms of air pollution [4], 
including second-hand smoke [6-7]. Lung cancer may be seen on chest radiographs and computed tomography (CT) scans. The diagnosis is confirmed by biopsy [8] which is usually performed by bronchoscope or CT-guidance. Treatment and long-term outcomes depend on the type of cancer, the stage (degree of spread), and the person's overall health, measured by performance status. Common treatments include surgery, chemotherapy, and radiotherapy. NSCLC is sometimes treated with surgery, whereas SCLC usually responds better to chemotherapy and radiotherapy [9]. Overall, $16.8 \%$ of people in the United States diagnosed with lung cancer survive five years after the diagnosis [10], while outcomes on average are worse in the developing world. Worldwide, lung cancer is the most common cause of cancerrelated death in men and women, and was responsible for 1.56 million deaths annually, as of 2012 [11]. Cancer develops following genetic damage to DNA and epigenetic changes. These changes affect the normal functions of the cell, including cell proliferation, programmed cell death (apoptosis) and DNA repair. As more damage accumulates, the risk of cancer increases. Smoking, radon gas, asbestos, air pollution and genetics are the main causes to increase the rate of lung cancer. Smoking and air pollution are by far the main contributor to lung cancer [12]. Cigarette smoke and air pollution extract of fuel contains at least 73 known carcinogens [13]. Across the developed world, $90 \%$ of lung cancer deaths in men during the year 2000 were attributed to smoking and pollution (70\% for women) [14]. Smoking and pollution accounts for $80-90 \%$ of lung cancer cases [1].

Pollution is the introduction of contaminants into the natural environment that cause adverse change. Pollution can take the form of chemical substances or energy, such as noise, heat or light. Pollutants, the components of pollution, can be either foreign substances/energies or naturally occurring contaminants. Pollution is often classed as point source or nonpoint source pollution. Nonpoint source (NPS) pollution refers to both water and air pollution from diffuse sources. Nonpoint source air pollution affects air quality from sources such as smokestacks or car tailpipes. Most automobiles in use today are propelled by an internal combustion engine, fueled by deflagration of gasoline (also known as petrol) or diesel. Both fuels are known to cause air pollution and are also blamed for contributing to climate change and global warming. Rapidly increasing oil prices, concerns about oil dependence, tightening environmental laws and restrictions on greenhouse gas emissions are propelling work on alternative power systems or increase the efficiency for automobiles. Internal combustion engines produce air pollution emissions, due to incomplete combustion of carbonaceous fuel. The effects of inhaling particulate matter have been studied in humans and animals and include asthma, lung cancer, cardiovascular issues, and premature death. There are, however, some additional products of the combustion process that include nitrogen oxides and sulfur and some un-combusted hydrocarbons, depending on the operating conditions and the fuel-air ratio [15-20].

To tune the fuel ration, modeling of an entire IC engine is a very important and complicated process because engines are nonlinear, multi inputs-multi outputs and time variant [21-23]. One purpose of accurate modeling is to save development costs of real engines and minimizing the risks of damaging an engine when validating controller designs. Nevertheless, developing a small model, for specific controller design purposes, can be done and then validated on a larger, more complicated model [24]. Analytical dynamic nonlinear modeling of internal combustion engine is carried out using elegant Euler-Lagrange method compromising accuracy and complexity. Belong as IC engine is nonlinear system, to adjust the fuel ratio nonlinear control methodology is the best candidate. One of the most important nonlinear safety controllers is computed fuel-ratio methodology which is used in nonlinear and certain systems. This methodology is used in wide range areas such as in safety control access process; in aerospace applications and in IC engines, because this methodology can 
solve some main challenging topics in safety control access such as resistivity to the external disturbance and stability. Even though, this methodology is used in wide range areas but, pure computed fuel method has an important drawbacks beside uncertain system and also in presence of external disturbance. Uncertainty in system can causes some problems about safety in industrial factory [25]. Although the fuzzy-logic control is not a new technique, its application in this current research is considered to be novel since it aimed for an automated dynamic-less response rather than for the traditional objective of uncertainties compensation [26]. The intelligent tracking control using the fuzzy-logic technique provides a cost-and-time efficient control implementation due to the automated dynamic-less input. This in turn would further inspire multi-uncertainties testing for IC engine [27]. To solve above challenges lowpass filter and fuzzy logic controller are the main candidates.

A low-pass filter is a filter that passes low-frequency signals and attenuates (reduces the amplitude of) signals with frequencies higher than the cutoff frequency. The actual amount of attenuation for each frequency varies depending on specific filter design. It is sometimes called a high-cut filter, or treble cut filter in audio applications. A low-pass filter is the opposite of a high-pass filter. A band-pass filter is a combination of a low-pass and a high-pass. Low-pass filters exist in many different forms, including electronic circuits (such as a hiss filter used in audio), anti-aliasing filters for conditioning signals prior to analog-todigital conversion, digital filters for smoothing sets of data, acoustic barriers, blurring of images, and so on. The moving average operation used in fields such as finance is a particular kind of low-pass filter, and can be analyzed with the same signal processing techniques as are used for other low-pass filters. Low-pass filters provide a smoother form of a signal, removing the short-term fluctuations, and leaving the longer-term trend. An optical filter can correctly be called a low-pass filter, but conventionally is called a longpass filter (low frequency is long wavelength), to avoid confusion.

In this research the active low pass filter is used to eliminate the high frequency oscillation in conventional computed fuel controller in presence of uncertainty and fuzzy logic controller is used to tune modified computed fuel coefficients. This paper is organized as follows; section 2, is served as an introduction to the dynamic of IC engines. Part 3 introduces and describes the methodology algorithm. Section 4 presents the simulation results and discussion of this algorithm applied to IC engine and the last part is described as conclusion.

\section{Theory}

Internal Combustion Engine: Modeling of an entire internal combustion (IC) engine is a very important and complicated process because internal combustion engines are nonlinear, multi inputs-multi outputs (MIMO) and time variant. There have been several engine controller designs over the previous years in which the main goal is to improve the efficiency and exhaust emissions of the automotive engine [15-18]. Specific applications of air to fuel (A/F) ratio control based on observer measurements in the intake manifold were developed by Benninger in 1991 [19]. Another approach was to base the observer on measurements of exhaust gases measured by the oxygen sensor and on the throttle position, which was researched by Onder. These observer ideas used linear observer theory. Hedrick also used the measurements of the oxygen sensor to develop a nonlinear, sliding mode approach to control the $\mathrm{A} / \mathrm{F}$ ratio [20]. All of the previous control strategies were applied to engines that used only port fuel injections, where fuel was injected in the intake manifold. Current production $\mathrm{A} / \mathrm{F}$ ratio controllers use closed loop feedback and feed forward control to achieve the desired stoichio metric mixture. These controllers use measurements from the oxygen sensor to control the desired amount of fuel that should be injected over the next engine cycle and have 
been able to control the A/F very well. In developing a valid engine model, the concept of the combustion process, abnormal combustion, and cylinder pressure must be understood. The combustion process is relatively simple and it begins with fuel and air being mixed together in the intake manifold and cylinder. This air-fuel mixture is trapped inside cylinder after the intake valve(s) is closed and then gets compressed. When the air-fuel mixture is compressed it causes the pressure and temperature to increase inside the cylinder. Unlike normal combustion, the cylinder pressure and temperature can rise so rapidly that it can spontaneously ignite the air-fuel mixture causing high frequency cylinder pressure oscillations. These oscillations cause the metal cylinders to produce sharp noises called knock, which it caused to abnormal combustion. The pressure in the cylinder is a very important physical parameter that can be analyzed from the combustion process. After the flame is developed, the cylinder pressure steadily rises, reaches a maximum point after TDC, and finally decreases during the expansion stroke when the cylinder volume increases. Since cylinder pressure is very important to the combustion event and the engine cycle in spark ignition engines, the development of a model that produces the cylinder pressure for each crank angle degree is necessary. Regarding to IC engine modeling, it is important to design nonlinear model-reference controller. In developing a valid engine model, the concept of the combustion process, abnormal combustion and cylinder pressure must be understood. The combustion process is relatively simple and it begins with fuel and air being mixed together in the intake manifold and cylinder. This air-fuel mixture is trapped inside cylinder after the intake valve(s) is closed and then gets compressed. When the air-fuel mixture is compressed it causes the pressure and temperature to increase inside the cylinder. In abnormal combustion, the cylinder pressure and temperature can rise so rapidly that it can spontaneously ignite the air-fuel mixture causing high frequency cylinder pressure oscillations. These oscillations cause the metal cylinders to produce sharp noises called knock, which it caused to abnormal combustion. The pressure in the cylinder is a very important physical parameter that can be analyzed from the combustion process. Since cylinder pressure is very important to the combustion event and the engine cycle in spark ignition engines, the development of a model that produces the cylinder pressure for each crank angle degree is necessary. The dynamic equations of IC engine can be written as:

$$
\begin{aligned}
& {\left[\begin{array}{c}
P F I \\
D I
\end{array}\right]=\left[\begin{array}{ll}
\dot{M}_{\text {air } 11} & \dot{M}_{\text {air } 12} \\
\dot{M}_{\text {air } 21} & \dot{M}_{\text {air } 22}
\end{array}\right]\left[\begin{array}{c}
\ddot{F R} \\
\ddot{\alpha}_{I}
\end{array}\right]+\left[\begin{array}{l}
P_{\text {motor }_{1}} \\
P_{\text {motor }_{2}}
\end{array}\right]\left[\begin{array}{ll}
\dot{F R} & \dot{\alpha}_{I}
\end{array}\right]+\left[\begin{array}{ll}
N_{11} & N_{12} \\
N_{21} & N_{22}
\end{array}\right] \times\left[\begin{array}{c}
F R \\
\dot{\alpha}_{I}
\end{array}\right]^{2}+} \\
& {\left[\begin{array}{l}
M_{a_{1}} \\
M_{a_{2}}
\end{array}\right]}
\end{aligned}
$$

There for to calculate the fuel ratio and equivalence ratio we can write:

$$
\begin{aligned}
& {\left[\begin{array}{c}
F \ddot{R}_{a} \\
\ddot{\alpha}_{I_{a}}
\end{array}\right]=\left[\begin{array}{ll}
\dot{M}_{\text {air } 11} & \dot{M}_{\text {air } 12} \\
\dot{M}_{\text {air } 21} & \dot{M}_{\text {air } 22}
\end{array}\right]^{-1}\left\{\left[\begin{array}{c}
P F I \\
D I
\end{array}\right]-\left\{\left[\begin{array}{l}
P_{\text {motor }_{1}} \\
P_{\text {motor }_{2}}
\end{array}\right]\left[\begin{array}{ll}
\dot{F R} & \dot{\alpha}_{I_{a}}
\end{array}\right]+\left[\begin{array}{ll}
N_{11} & N_{12} \\
N_{21} & N_{22}
\end{array}\right] \times\right.\right.} \\
& \left.\left.\left[\begin{array}{c}
F \dot{R}_{a} \\
\dot{\alpha}_{I_{a}}
\end{array}\right]^{2}+\left[\begin{array}{c}
M_{a_{1}} \\
M_{a_{2}}
\end{array}\right]\right\}\right\}
\end{aligned}
$$

To solve $\dot{\boldsymbol{M}}_{\text {air }}$,

$$
\dot{M}_{\text {air }}=\left[\begin{array}{ll}
\dot{M}_{\text {air } 11} & \dot{M}_{\text {air } 12} \\
\dot{M}_{\text {air } 21} & \dot{M}_{\text {air 22 }}
\end{array}\right] \quad \text { Where } \dot{M}_{\text {air } 12}=\dot{M}_{\text {air } 21}
$$

Where $\dot{M}_{\text {air }}$ is the ratio of the mass of air.

Matrix $P_{\text {motor }}$ is a $1 \times 2$ matrix: 


$$
P_{\text {motor }}=\left[\begin{array}{l}
\boldsymbol{P}_{1} \\
\boldsymbol{P}_{2}
\end{array}\right]
$$

Matrix engine angular speed matrix $(N)$ is a $2 \times 2$ matrix

$$
N=\left[\begin{array}{ll}
N_{11} & N_{12} \\
N_{21} & N_{22}
\end{array}\right]
$$

Where,

Matrix mass of air in cylinder for combustion matrix $\left(M_{a}\right)$ is a $1 \times 2$ matrix.

$$
M_{a}=\left[\begin{array}{l}
\boldsymbol{M}_{\boldsymbol{a}_{1}} \\
\boldsymbol{M}_{\boldsymbol{a}_{2}}
\end{array}\right]
$$

The above target equivalence ratio calculation will be combined with fuel ratio calculation that will be used for controller design purpose. Figure 1 shows the IC engine.

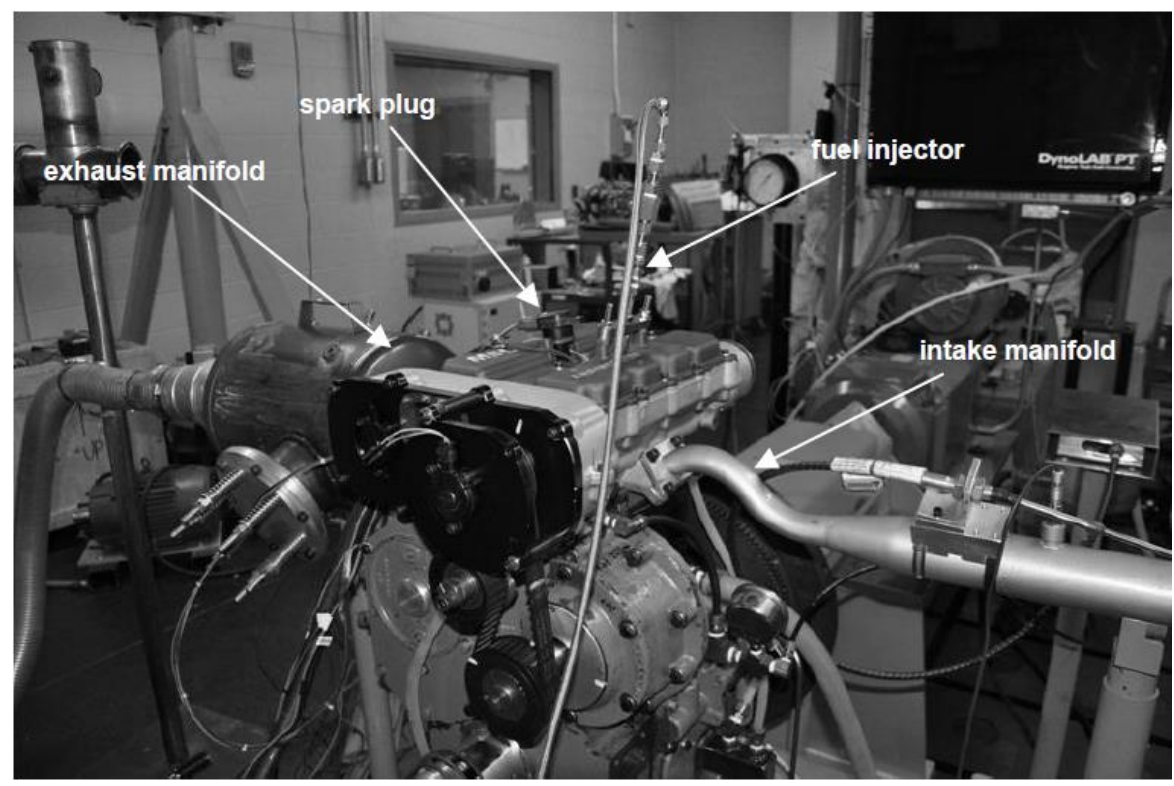

Figure 1. Test Engine

\section{Methodology}

Computed fuel-ratio controller (CFC) is a powerful nonlinear controller and widely used in control of nonlinear systems. It works based on feedback linearization method and computes the required port to fuel ratio using the nonlinear feedback control law. This controller works very well when all dynamic and physical parameters are known but when systems have variation in dynamic parameters it has many challenges. In practice, IC engine parameters are unknown and time variant, therefore, computed fuel like controller used to compensate dynamic equation of system. When all dynamic and physical parameters are known, this controller works fantastically; practically a large amount of systems have uncertainties, therefore computed fuel like controller is the best case to solve this challenge. The central idea of computed fuel-ratio controller (CFC) is feedback linearization so, originally this algorithm is called feedback linearization controller. It has assumed that the desired motion trajectory for the automotive engine $\boldsymbol{F} \boldsymbol{R}_{\boldsymbol{d}}(\boldsymbol{t})$, as determined, by a path planner. Defines the tracking error as:

$$
e(t)=F R_{d}(t)-F R_{a}(t)
$$


Where $\boldsymbol{e}(\boldsymbol{t})$ is error, $\boldsymbol{F} \boldsymbol{R}_{\boldsymbol{d}}(\boldsymbol{t})$ is desired input variable, that in our system is desired rate of fuel ratio, $\boldsymbol{F} \boldsymbol{R}_{\boldsymbol{a}}(\boldsymbol{t})$ is actual rate of fuel-ratio. If an alternative linear state-space equation in the form $\quad \dot{\boldsymbol{x}}=\boldsymbol{A} \boldsymbol{x}+\boldsymbol{B} \boldsymbol{U}$ can be defined as

$$
\dot{x}=\left[\begin{array}{ll}
\mathbf{0} & \boldsymbol{I} \\
\mathbf{0} & \mathbf{0}
\end{array}\right] \boldsymbol{x}+\left[\begin{array}{l}
\mathbf{0} \\
\boldsymbol{I}
\end{array}\right] \boldsymbol{U}
$$

With $U=-\dot{M}_{\text {air }}{ }^{-1}(\boldsymbol{F} \boldsymbol{R}) \cdot \boldsymbol{N}(\boldsymbol{F} \boldsymbol{R}, \boldsymbol{F} \boldsymbol{R})+\dot{\boldsymbol{M}}_{\text {air }}{ }^{-1}(\boldsymbol{F} \boldsymbol{R}) . \boldsymbol{P F I}$ and this is known as the Brunousky canonical form. By equation (7) and (8) the Brunousky canonical form can be written in terms of the state $\boldsymbol{x}=\left[\boldsymbol{e}^{T} \dot{e}^{T}\right]^{T}$ as:

$$
\frac{d}{d t}\left[\begin{array}{l}
e \\
\dot{e}
\end{array}\right]=\left[\begin{array}{ll}
0 & I \\
0 & 0
\end{array}\right] \cdot\left[\begin{array}{l}
e \\
\dot{e}
\end{array}\right]+\left[\begin{array}{l}
0 \\
I
\end{array}\right] U
$$

With

$$
U=\ddot{F} R_{d}+\dot{M}_{\text {air }}{ }^{-1}(F R) \cdot\{N(F R . F R)-P F I\}
$$

Then compute the required PFI using inverse of equation (10), is;

$$
P F I=\dot{M}_{\text {air }}(F R)\left(F \ddot{R}_{d}-U\right)+N(F R, F R)
$$

This is a nonlinear feedback control law that guarantees tracking of desired rate. Selecting proportional-plus-derivative (PD) feedback for $\boldsymbol{U}(\boldsymbol{t})$ results in the PD-computed fuel-ratio controller;

$$
P F I=\dot{M}_{\text {air }}(F R)\left(\ddot{F R}_{d}+K_{v} \dot{e}+K_{p} e\right)+N(F R, \dot{F R})
$$

and the resulting linear error dynamics are

$$
\left(\ddot{F} R_{d}+K_{v} \dot{e}+K_{p} \boldsymbol{e}\right)=0
$$

According to the linear system theory, convergence of the tracking error to zero is guaranteed. Where $\boldsymbol{K}_{\boldsymbol{p}}$ and $\boldsymbol{K}_{\boldsymbol{v}}$ are the controller gains. Regarding to CFC it has challenge in presence of uncertainty and cannot guarantee the stability of fuel ratio. To improve this challenge fuzzy logic is a good candidate. This theory is used to estimate the dynamic parameters in presence of uncertainty.

Based on foundation of fuzzy logic methodology; fuzzy logic controller has played important rule to design nonlinear controller for nonlinear and uncertain systems. However the application area for fuzzy control is really wide, the basic form for all command types of controllers consists of;

- Input fuzzification (binary-to-fuzzy $[\mathrm{B} / \mathrm{F}]$ conversion)

- Fuzzy rule base (knowledge base)

- Inference engine

- Output defuzzification (fuzzy-to-binary [F/B] conversion)

The fuzzy inference engine offers a mechanism for transferring the rule base in fuzzy set which it is divided into two most important methods, namely,

- Mamdani method

- $\quad$ Sugeno method

Mamdani method is one of the common fuzzy inference systems and he designed one of the first fuzzy controllers to control of system engine. Mamdani's fuzzy inference system is divided into four major steps:

- Fuzzification

- Rule evaluation

- Aggregation of the rule outputs

- Defuzzification

Michio Sugeno uses a singleton as a membership function of the rule consequent part. The following definition shows the Mamdani and Sugeno fuzzy rule base 


\section{if $x$ is $A$ and $y$ is $B$ then $z$ is $C^{\prime}$ mamdani'}

if $x$ is $A$ and $y$ is $B$ then $z$ is $f(x, y)^{\prime}$ 'sugeno'

When $x$ and $y$ have crisp values fuzzification calculates the membership degrees for antecedent part. Rule evaluation focuses on fuzzy operation $(A N D / O R)$ in the antecedent of the fuzzy rules. The aggregation is used to calculate the output fuzzy set and several methodologies can be used in fuzzy logic controller aggregation, namely

- Max-Min aggregation

- Sum-Min aggregation

- Max-bounded product

- Max-drastic product

- Max-bounded sum

- Max-algebraic sum

- Min-max

In this research Max-min aggregation is selected which defined as below;

$$
\mu_{U}\left(x_{k}, y_{k}, U\right)=\mu_{\cup_{i=1}^{r} F R^{i}}\left(x_{k}, y_{k}, U\right)=\max \left\{\min _{i=1}^{r}\left[\mu_{R p q}\left(x_{k}, y_{k}\right), \mu_{p_{m}}(U)\right]\right\}
$$

where $r$ is the number of fuzzy rules activated by $x_{k}$ and $y_{k}$ and also $\mu_{\cup_{i=1}^{r} F R^{i}}\left(x_{k}, y_{k}, U\right)$ is a fuzzy interpretation of $i-t h$ rule. Defuzzification is the last step in the fuzzy inference system which it is used to transform fuzzy set to crisp set. Consequently defuzzification's input is the aggregate output and the defuzzification's output is a crisp number. Two most common defuzzification methods are;

- Centre of gravity method $(C O G)$

- Centre of area method (COA)

In this research $C O G$ method used as the follow formulation;

$$
\operatorname{CoG}\left(x_{k}, y_{k}\right)=\frac{\sum_{i} U_{i} \sum_{j=1}^{r} \cdot \mu_{u}\left(x_{k}, y_{k}, U_{i}\right)}{\sum_{i} \sum_{j=1}^{r} \cdot \mu_{u}\left(x_{k}, y_{k}, U_{i}\right)}
$$

Where $\operatorname{COG}\left(x_{k}, y_{k}\right)$ illustrates the crisp value of defuzzification output, $U_{i} \in U$ is discrete element of an output of the fuzzy set, $\mu_{U} \cdot\left(x_{k}, y_{k}, U_{i}\right)$ is the fuzzy set membership function, and $r$ is the number of fuzzy rules. In this research fuzzy logic part has two roles:

- System's dynamic estimator

- Tuning the coefficient

As can be seen, it is a controller that contains a PD-type fuzzy. It has a double inputs, error signal $\boldsymbol{e}(\boldsymbol{k})$, which internally yields another fuzzy controller input, change in error signal $\Delta \boldsymbol{e}(\boldsymbol{k})$. The following formulation shows the rule-base which design in this research:

1. $e(k) \in Z E$ and $\triangle e(k) \in Z D E \rightarrow P F I_{F u z z y}=Z_{1}$,

2. $e(k) \notin Z E$ and $\triangle e(k) \in Z D E \rightarrow P F I_{\text {fuzzy }}=Z_{2}$,

where $\mathrm{ZE}$ and $\mathrm{ZDE}$ are zero fuzzy subsets of the fuzzy controller inputs. In a variant of the discussed fuzzy controller, a PD-type fuzzy controller can take the role of the PD controller. Then the PD-type fuzzy controller would act only in the case of sufficiently large reference input changes. Regarding the software implementation, special attention must be paid to the switching of operating modes, as the fuzzy controller contains two control algorithms, which may work either separately or together. Seven linguistic subsets have been defined for both inputs: NL, NM, NS, Z, PS, PM, and PL. Based on knowledge about the characteristics of the position control loop, the maximum values for both inputs and the output of the fuzzy position controller can be estimated. The distribution of membership functions related to normalized $e$ and $\Delta e$ subsets is shown in Figure 2. Different forms of membership functions 
can be used, but experiments have proved that trapezoidal forms contribute the most to achieving lower sensitivity to parameter variations in the designed fuzzy controller.
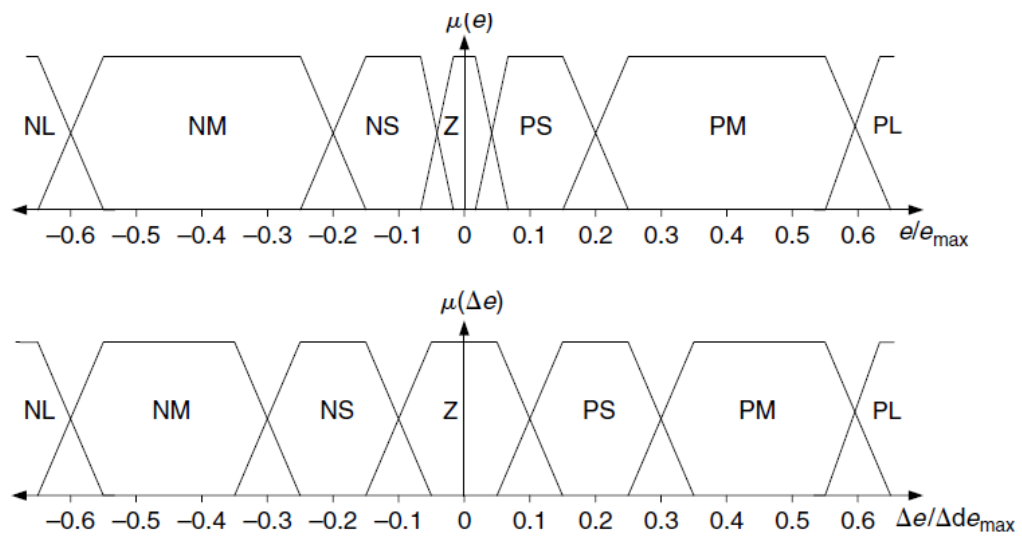

Figure 2. Input Membership Functions of a Hybrid Fuzzy Controller

The universe of discourse of the fuzzy controller output is discrete and contains 15 uniform fuzzy subsets. The distribution of accompanying membership functions is symmetrical and slightly nonlinear because of one extra subset added next to the zero subset to ensure a smooth change of operating modes defined by relations (Table. 1). The corresponding centroids have the following values: $-1,-0.667,-0.5,-0.333,-0.167,-0.0083,-0.0042,0$, $0.0042,0.0083,0.167,0.333,0.5,0.667$, and 1 . The fuzzy rule table of the hybrid controller fuzzy controller is shown in Table 1.

Table 1. The Fuzzy Rule Table of a Hybrid Fuzzy Controller

$$
\begin{aligned}
& \text { NLE NME NSE ZE PSE PME PLE } \\
& \begin{array}{llllllll}
\text { NLDE } & 1 & 1 & 0.667 & 0.5 & 0.333 & 0.0083 & 0
\end{array} \\
& \begin{array}{llllllll}
\text { NMDE } & 1 & 1 & 0.667 & 0.167 & 0.0083 & -0.0042 & -0.0083
\end{array} \\
& \begin{array}{llllll}
\text { NSDE } & 1 & 0.667 & 0.167 & -0.333 & -0.5
\end{array} \\
& \begin{array}{llllllll}
\text { ZDE } & 0.833 & 0.333 & 0.0083 & 0 & 0 & -0.333 & -0.833
\end{array} \\
& \begin{array}{llllllll}
\text { PSDE } & 0.667 & 0.333 & 0 & -0.0083 & -0.167 & -0.667 & -1
\end{array} \\
& \begin{array}{llllllll}
\text { PMDE } & 0.0083 & -0.0083 & -0.167 & -0.333 & -0.667 & -1 & -1
\end{array} \\
& \begin{array}{llllllll}
\text { PLDE } & -0.0083 & -0.167 & -0.333 & -0.5 & -0.667 & -1 & -1
\end{array} \\
& P F I=\dot{M}_{a i r}(F R)\left(\ddot{F R}_{d}+K_{v} \dot{e}+K_{p} e\right)+N(F R, \dot{F R}) \\
& W=\left(K_{v} \dot{e}+K_{p} e\right) \\
& W_{\text {new }}=\left((1-\alpha) \times K_{v} \dot{e}+\alpha \times K_{p} e\right) \\
& W_{n e w}=\left(\alpha \times K_{p} e-\alpha \times K_{v} \dot{e}+K_{v} \dot{e}\right)
\end{aligned}
$$

Where $\boldsymbol{\alpha}$ is fuzzy output. However computed fuel like controller has many advantages compare to computed fuel-ratio controller but it has limitation in presence of uncertainty. To solve this challenge filter based computed fuel like control is the main candidate. 
An active filter generally uses an operational amplifier (op-amp) within its design and an Op-amp has high input impedance, low output impedance and a voltage gain determined by the resistor network within its feedback loop. Unlike a passive high pass filter which has in theory an infinite high frequency response, the maximum frequency response of an active filter is limited to the Gain/Bandwidth product (or open loop gain) of the operational amplifier being used. Still, active filters are generally easier to design than passive filters; they produce good performance characteristics, very good accuracy with a steep roll-off and low noise when used with a good circuit design. The most common and easily understood active filter is the Active Low Pass Filter. Its principle of operation and frequency response is exactly the same as those for the previously seen passive filter, the only difference this time is that it uses an op-amp for amplification and gain control. The simplest form of a low pass active filter is to connect an inverting or non-inverting amplifier. This first-order low pass active filter, consists simply of a passive RC filter stage providing a low frequency path to the input of a non-inverting operational amplifier. The amplifier is configured as a voltagefollower (Buffer) giving it a DC gain of one, $\mathrm{Av}=+1$ or unity gain as opposed to the previous passive RC filter which has a DC gain of less than unity.

The advantage of this configuration is that the op-amps high input impedance prevents excessive loading on the filters output while its low output impedance prevents the filters cutoff frequency point from being affected by changes in the impedance of the load. While this configuration provides good stability to the filter, its main disadvantage is that it has no voltage gain above one. However, although the voltage gain is unity the power gain is very high as its output impedance is much lower than its input impedance. If a voltage gain greater than one is required we can use the following filter circuit. As with the passive filter, a firstorder Low Pass Active Filter can be converted into a second-order low pass filter simply by using an additional $\mathrm{RC}$ network in the input path. The frequency response of the second-order low pass filter is identical to that of the first-order type except that the stop band roll-off will be twice the first-order filters at $40 \mathrm{~dB} /$ decade $(12 \mathrm{~dB} /$ octave). Therefore, the design steps required of the second-order active low pass filter are the same. To reduce the oscillation in presence of uncertainty the second order active filter is used in conventional computed fuel controller. The standard form of a second-order, low-pass filter is given as:

$$
L P F=\frac{T_{L P(0)} \times\left(\omega_{0}\right)^{2}}{S^{2}+\frac{\omega_{0}}{Q} S+\left(\omega_{0}\right)^{2}}
$$

where $\boldsymbol{T}_{\boldsymbol{L P}(\mathbf{0})}$ is the value of $\boldsymbol{T}_{\boldsymbol{L P}(\boldsymbol{s})}$ at dc, $\boldsymbol{\omega}_{\mathbf{0}}$ is the pole frequency, and $Q$ is the pole $Q$ or the pole quality factor.

\section{Result and Discussion}

Outdoor air pollution has a large effect on increasing the risk of lung cancer. To control of this challenge fuel to air ratio is the main factor in IC engine. To optimize it, filter-based computed fuel like controller is used as a main controller. To validate this research computed fuel control and proposed method is compared.

Certain Fuel Ratio Regulation: regarding to Figure 3, CFC and proposed method are compared. The reference test in this research is 0.6. According to below graph, CFC has $25 \%$ overshoot and it caused to increase the air pollution at initial time. Proposed methodology can regulate (eliminate) overshoot from $25 \%$ to zero. Both of methods have the same error performance, near to the zero. 


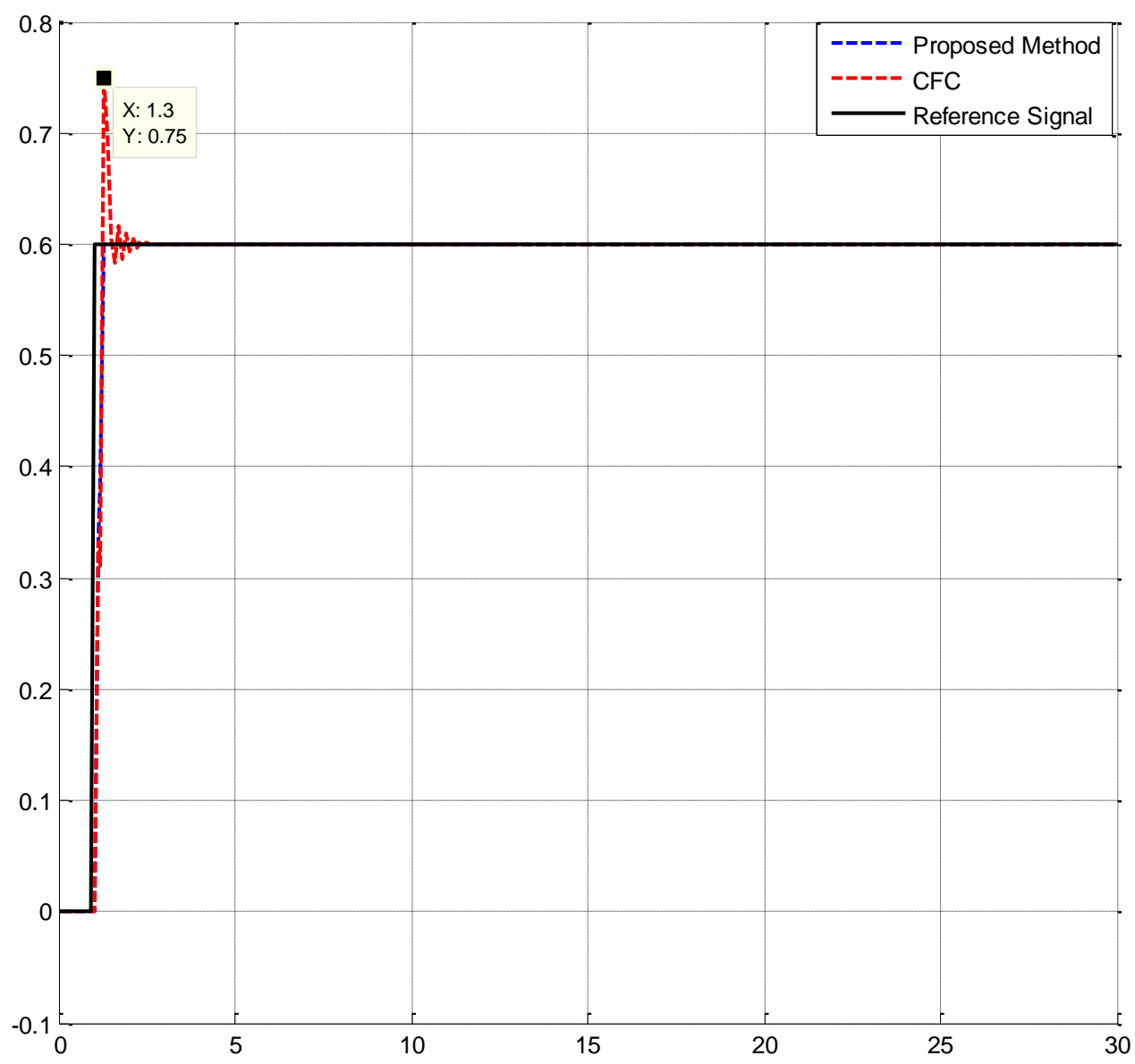

Figure 3. Certain Fuel Ratio Regulation

Port Fuel Injection (PFI) Performance: Figure 4 shows the graph of PFI performance. This item is very important to energy optimization and also the rule of controller to regulate the fuel ratio and finally reduce the air pollution. Regarding to Figure 4, after 5 seconds the PFI in CFC is about -0.1 and caused to increase the fuel consumption. In proposed method after 5 seconds the PFI is zero and caused to reduce the fuel consumption that caused to reduce the air pollution. 


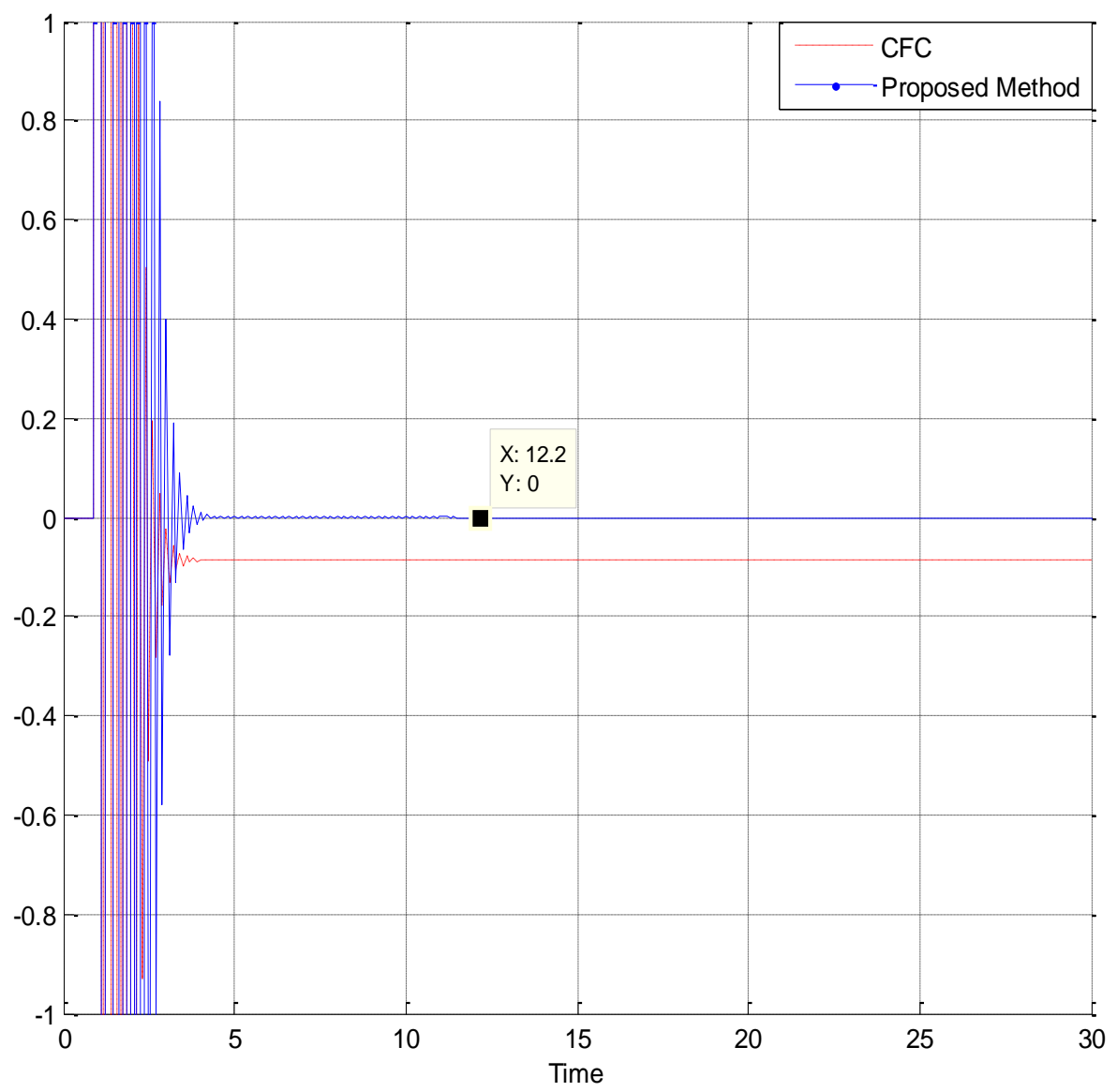

Figure 4. Certain Port to Fuel Ratio Performance

Regarding to Figures 3 and 4, however proposed method is more stable and reliable in certain condition and caused to reduce the fuel consumption but CFC also has good performances.

Uncertain Fuel Ratio Regulation (Robustness Test): Figure 5 shows the power disturbance elimination in proposed method and CFC. Regarding to the following Figure in presence of uncertainty, the overshoot in proposed method grow up from zero to about $5 \%$ and CFC overshoot's is increase from $25 \%$ to $28.5 \%$. Regarding to the following graph, CFC has moderate fluctuations compared to proposed method. This fluctuation due to the rapid increases in fuel consumption and followed by increase the air pollution and increases the risk of lung cancer. Proposed method is robust against uncertainty and in this state the error also near to the zero. 


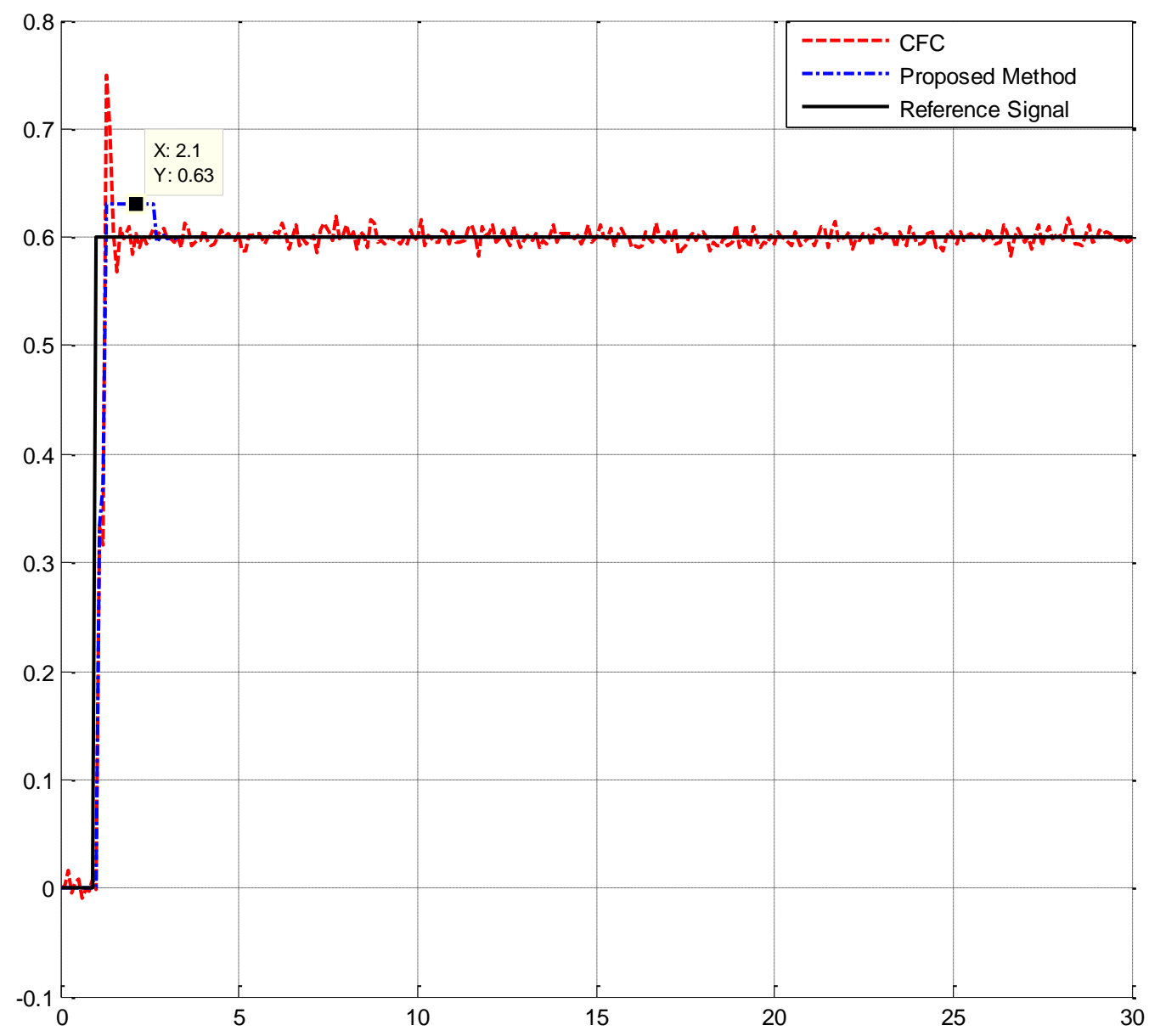

Figure 5. Certain Fuel Ratio Regulation

Port Fuel Injection (PFI) Performance in Presence of Uncertainty: Figure 6 shows the graph of PFI performance. This item is very important to energy optimization and also the rule of controller to regulate the fuel ratio and finally reduce the air pollution. Regarding to the following graph, CFC has too much fluctuations in presence of external disturbance. According to following graph, proposed method is more stable and robust than CFC in presence of uncertainty. 


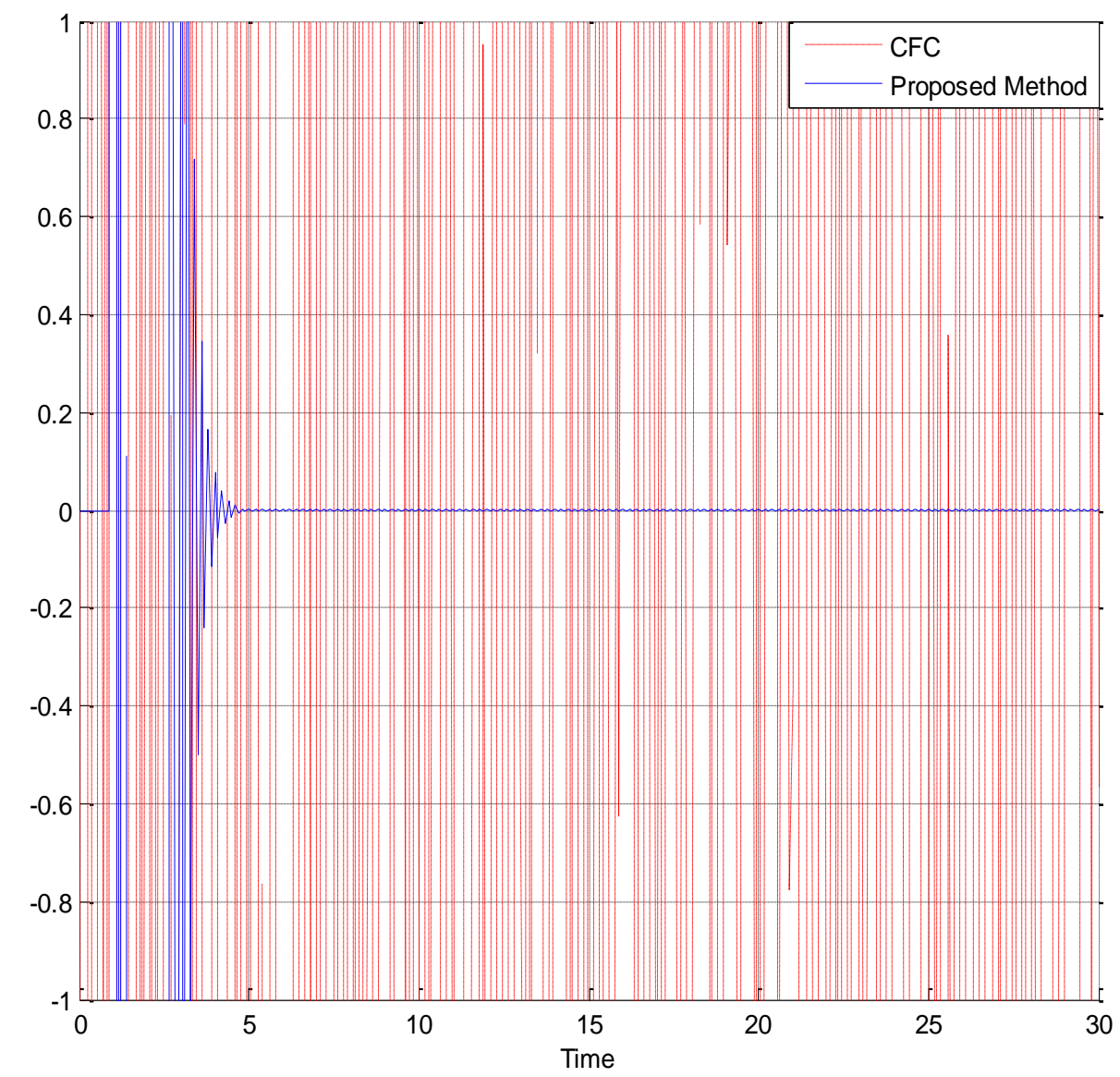

Figure 6. Port Fuel Injection (PFI) Performance in Presence of Uncertainty

\section{Conclusion}

According to this research, tuning the fuel ratio to decrease the air pollution and finally prevent the risk of lung cancer progression is introduced. The vast majority of cancer cases are due to environmental risk factors, and many, but not all, of these environmental factors are controllable lifestyle choices. Thus, cancer is considered a largely preventable disease. Greater than $30 \%$ of cancer deaths could be prevented by avoiding risk factors including: air pollution and smoking, overweight / obesity, an insufficient diet, physical inactivity, alcohol and sexually transmitted infections. To control the main factor of cancer, namely; air pollution, filter based computed like fuel ratio controller is used for automotive engine. Regarding to this design the rate of fuel consumption can be reducing and this method can regulate the fuel ratio in certain and uncertain condition. The rates of fluctuations are decreased compare to CFC. The proposed method has two important factors: low pass filter that used to filtering the high frequency oscillation and fuzzy logic part that caused to estimate the dynamic parameters in presence of uncertainty. 


\section{Acknowledgement}

The authors would like to thank the anonymous reviewers for their careful reading of this paper and for their helpful comments. This work was supported by the Iranian Institute of Advance Science and Technology Program of Iran under grant no. 2014-Persian Gulf-1C. Iranian center of Advance Science and Technology (IRAN SSP) is one of the independent research centers specializing in research and training across of Control and Automation, Electrical and Electronic Engineering, and Mechatronics \& Robotics in Iran. At IRAN SSP research center, we are united and energized by one mission to discover and develop innovative engineering methodology that solve the most important challenges in field of advance science and technology. The IRAN SSP Center is instead to fill a long standing void in applied engineering by linking the training a development function one side and policy research on the other. This center divided into two main units:

- $\quad$ Education unit

- $\quad$ Research and Development unit

\section{References}

[1]. L. Horn, W. Pao and D. H. Johnson, "Chapter 89", In Longo, DL, Kasper, DL, Jameson, JL, Fauci, AS, Hauser, SL, Loscalzo, J. Harrison's Principles of Internal Medicine (18th ed.), McGraw-Hill, ISBN 0-07174889-X, (2012).

[2]. "Lung Carcinoma: Tumors of the Lungs", Merck Manual Professional Edition, Online edition. Retrieved, vol. 15, (2007) August.

[3]. M. J. Thun, L. M. Hannan, L. L. Adams-Campbell, et al., "Lung cancer occurrence in never-smokers: an analysis of 13 cohorts and 22 cancer registry studies", PLoS Medicine, vol. 5, no. 9, (2008) September.

[4]. A. J. Alberg and J. M. Samet, "Chapter 46". Murray \& Nadel's Textbook of Respiratory Medicine (5th ed.), Saunders Elsevier. ISBN 978-1-4160-4710-0, (2010).

[5]. K. M. O'Reilly, A. M. Mclaughlin, W. S Beckett and P. J. Sime, "Asbestos-related lung disease", American Family Physician, PMID 17375514, vol. 75, no. 5, (2007) March, pp. 683-688.

[6]. R. H. Carmona, "The Health Consequences of Involuntary Exposure to Tobacco Smoke: A Report of the Surgeon General", U.S. Department of Health and Human Services, Secondhand smoke exposure causes disease and premature death in children and adults who do not smoke, Retrieved 2014-06-16, (2006) June 27.

[7]. "Tobacco Smoke and Involuntary Smoking" (PDF), IARC Monographs on the Evaluation of Carcinogenic Risks to Humans (WHO International Agency for Research on Cancer) 83. 2002. There is sufficient evidence that involuntary smoking (exposure to secondhand or 'environmental' tobacco smoke) causes lung cancer in humans. ... Involuntary smoking (exposure to secondhand or 'environmental' tobacco smoke) is carcinogenic to humans (Group 1).

[8]. C. Lu, A. Onn, A. A. Vaporciyan, et al., "78: Cancer of the Lung", Holland-Frei Cancer Medicine (8th ed.), People's Medical Publishing House, ISBN 978-1-60795-014-1, (2010).

[9]. S. Chapman, G. Robinson J. Stradling and S. West, "Chapter 31", Oxford Handbook of Respiratory Medicine (2nd ed.), Oxford University Press. ISBN 978-0-19-954516-2, (2009).

[10]. "Surveillance, Epidemiology and End Results Program". National Cancer Institute. Retrieved, (2014) July 15.

[11]. "World Cancer Report 2014", World Health Organization, (2014), pp. Chapter 1.1.ISBN 9283204298.

[12]. H. K. Biesalski, B. Bueno de Mesquita, A. Chesson, et al., "European Consensus Statement on Lung Cancer: risk factors and prevention, Lung Cancer Panel", CA Cancer J Clin (Smoking is the major risk factor, accounting for about $90 \%$ of lung cancer incidence, vol. 48, no. 3, (1998), pp. 167-176.

[13]. S. S. Hecht, "Lung carcinogenesis by tobacco smoke". International Journal of Cancer, vol. 131, no. 12, (2012).

[14]. R. Peto, A. D. Lopez J. Boreham, et al., "Mortality from smoking in developed countries 1950-2000: Indirect estimates from National Vital Statistics", Oxford University Press. ISBN 0-19-262535-7, (2006).

[15]. J. Heywood, "Internal Combustion Engine Fundamentals", McGraw-Hill, New York, (1998).

[16]. J. G. Rivard, "Closed-loop Electronic Fuel Injection Control of the IC Engine," in Society of Automotive Engineers, (1973).

[17]. J. F. Cassidy, et al., "On the Design of Electronic Automotive Engine Controls using linear Quadratic Control Theory," IEEE Trans on Control Systems, vol. AC-25, (1980) October. 
[18]. W. E. Powers, "Applications of Optimal Control and Kalman Filtering to Automotive Systems," International Journal of Vehicle Design, vol. Applications of Control Theory in the Automotive Industry, (1983).

[19]. N. F. Benninger, et al., "Requirements and Perfomance of Engine Management Systems under Transient Conditions," in Society of Automotive Engineers, (1991).

[20]. N. F. Benninger, et al., "Requirements and Perfomance of Engine Management Systems under Transient Conditions," in Society of Automotive Engineers, (1991).

[21]. C. H. Onder, et al., "Model-Based Multivariable Speed and Air-to-Fuel Ratio Control of an SI Engine," in Society of Automotive Engineers, (1993).

[22]. S. B. Cho, et al., "An Observer-based Controller Design Method for Automotive Fuel-Injection Systems," in American Controls Conference, (1993), pp. 2567-2571.

[23]. T. Kume, et al., "Combustion Technologies for Direct Injection SI Engine," in Society of Automotive Engineers, (1996).

[24]. S. Soltani and F. Piltan, "Design Artificial Nonlinear Controller Based on Computed Torque like Controller with Tunable Gain”, World Applied Science Journal (WASJ), vol. 14, no. 9, (2011), pp. 1306-1312.

[25]. F. Piltan, S. Emamzadeh, S. Heidari, S. Zahmatkesh and K. Heidari, "Design Artificial Intelligent Parallel Feedback Linearization of PID Control with Application to Continuum Robot", International Journal of Engineering and Manufacturing, vol. 3, no. 2, (2013), pp. 51-72, DOI: 10.5815/ijem.2013.02.04.

[26]. A. Jahed, F. Piltan, H. Rezaie and B. Boroomand, "Design Computed Torque Controller with Parallel Fuzzy Inference System Compensator to Control of Robot Manipulator", International Journal of Information Engineering and Electronic Business, vol. 5, no. 3, (2013), pp. 66-77, DOI: 10.5815/ijieeb.2013.03.08.

[27]. M. Kazeminasab, F. Piltan, Z. Esmaeili, M. Mirshekaran and A. Salehi ,"Design Parallel Fuzzy Partly Inverse Dynamic Method plus Gravity Control for Highly Nonlinear Continuum Robot", IJISA, vol. 6, no. 1, (2014), pp. 112-123, DOI: 10.5815/ijisa.2014.01.12.
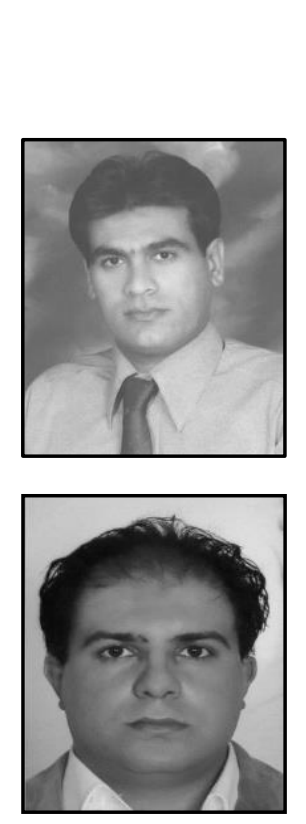

\section{Author}

Amirzubir Sahamijoo is currently a co-researcher in the Intelligent System and Robotic Lab at Iranian Institute of Advance Science and Technology (IRAN SSP) of the program for Prevent the Risk of Lung Cancer Progression Based on Fuel Ratio Optimization.

Farzin Piltan was born on 1975, Shiraz, Iran. In 2004 he is jointed Institute of Advance Science and Technology, Research and Development Center, IRAN SSP. Now he is a dean of Intelligent Control and Robotics Lab. He is led of team (47 researchers) to design and build of nonlinear control of industrial robot manipulator for experimental research and education and published about 54 Papers in this field since 2010 to 2012 , team supervisor and leader (9 researchers) to design and implement intelligent tuning the rate of fuel ratio in internal combustion engine for experimental research and education and published about 17 Journal papers since 2011 to 2013, team leader and advisor (34 researchers) of filtering the hand tremors in flexible surgical robot for experimental research and education and published about 31 journal papers in this field since 2012 to date, led of team (21 researchers) to design high precision and fast dynamic controller for multi-degrees of freedom actuator for experimental research and education and published about 7 journal papers in this field since 2013 to date, led of team ( 22 researchers) to research of full digital control for nonlinear systems (e.g., Industrial Robot 

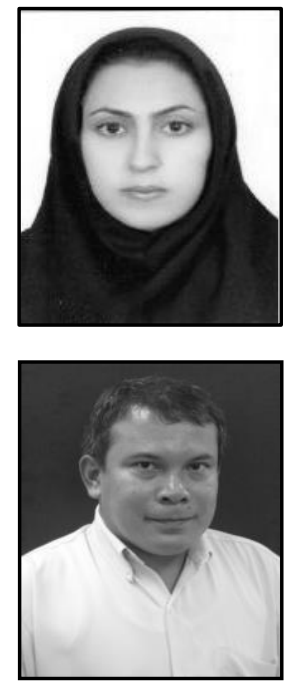

Manipulator, IC Engine, Continuum Robot, and Spherical Motor) for experimental research and education and published about 4 journal papers in this field since 2010 to date and finally led of team (more than 130 researchers) to implementation of Project Based-Learning project at IRAN SSP research center for experimental research and education, and published more than 110 journal papers since 2010 to date. In addition to 7 textbooks, Farzin Piltan is the main author of more than 115 scientific papers in refereed journals. He is editorial review board member for 'international journal of control and automation (IJCA), Australia, ISSN: 2005-4297; 'International Journal of Intelligent System and Applications (IJISA)', Hong Kong, ISSN:2074-9058; 'IAES international journal of robotics and automation, Malaysia, ISSN:2089-4856; 'International Journal of Reconfigurable and Embedded Systems', Malaysia, ISSN:2089-4864. His current research interests are nonlinear control, artificial control system and applied to FPGA, robotics and artificial nonlinear control and IC engine modeling and control.

Sareh Mohammadi Jabery is currently a co-researcher in the Intelligent System and Robotic Lab at Iranian Institute of Advance Science and Technology (IRAN SSP) of the program for Prevent the Risk of Lung Cancer Progression Based on Fuel Ratio Optimization.

Nasri Sulaiman received The B.Eng From University Of Putra Malaysia In 1994, M.Sc., From University Of Southampton, Uk In1999, And Phd Degrees From University Of Edinburgh, Uk In 2007, Respectively. He has more than 65 journal and conference papers. He is Currently A Senior Lecturer In The Department Of Electrical Engineering At University Putra Malaysia Of The Program For Signal Processing, And Evolvable Hardware (EHW) And Also Is Head Of Control And Automation Laboratory, Iranian Institute Of Advanced Science And Technology, Shiraz, Iran. He Is An Advisor In Spherical Motor Control. 